\title{
A Inversão do Cotidiano: Práticas Sociais e Rupturas na Vida Urbana Contemporânea*
}

\author{
Rogerio Proença Leite
}

Professor associado da Universidade Federal de Sergipe (UFS). E-mail: rproleite@gmail.com

\section{INTRODUÇÃO}

E mbora se reconheça que o cotidiano se constitui mediante certa rotinização, gostaria de poder reafirmar, em perspectiva já proposta por outros autores, de que a contingência não apenas lhe é igualmente constitutiva, como lhe é imprescindível. Desse modo, retomo, aqui, a perspectiva de José Machado Pais, quando afirma que "[...] do ponto de vista de uma sociologia do cotidiano, não é apenas importante aquilo que fixa regularidades da vida social; é também importante aquilo que a perturba" (2007:84).

Essa "perturbação" dos fluxos regulares da rotinização tem, a meu ver, duplo valor heurístico para a compreensão da vida cotidiana no contexto contemporâneo: 1) por possibilitar o entendimento de certas ações cotidianas que não se circunscrevem à normatividade predominante nos contextos de vida pública; e 2) por permitir compreender a

\footnotetext{
* A primeira versão deste artigo, que resulta de pesquisa realizada com bolsa do Conselho Nacional de Desenvolvimento Científico e Tecnológico (CNPq), foi apresentada na mesa-redonda "A Vida Cotidiana na Metrópole Contemporânea como um Problema da Sociologia", no 14ํㅡㄹ Congresso Brasileiro de Sociologia, da Sociedade Brasileira de Sociologia (SBS), Rio de Janeiro, 2009; a mesa foi coordenada por Fraya Frehse (USP) e contou, ainda, com a participação de José de Souza Martins (USP) e José Machado Pais (Lisboa). Gostaria de agradecer às pertinentes críticas dos pareceristas da revista DADOS, cujas sugestões foram, praticamente todas, incorporadas ao texto.
}

DADOS - Revista de Ciências Sociais, Rio de Janeiro, vol. 53, n-3, 2010, pp. 737 a 756. 
dimensão profundamente conflitante da vida urbana contemporânea e os distintos mecanismos que subsidiam as práticas sociais que alteram a vida cotidiana.

Meu argumento, portanto, gravita em torno da idéia de que o cotidiano, na experiência urbana contemporânea, é contingente na normatividade e imprevisível na rotinização. Mais do que uma configuração fluída - algo como lapsos de impulsividades não esperados, em contraposição à severidade normativa e suas respectivas condutas esperadas, caráter esse reconhecido por autores de diferentes matizes teóricos, como Certeau (1994); Pais (2007); Martins (2000); e Heller (2000) - refiro-me à existência de condutas deliberadamente ambíguas que são fugidias ao enquadramento conceitual binário, do tipo conduta normativa, ou ação desregrada. Não pretendo, com essa assertiva, negar inteiramente o caráter recursivo das ações cotidianas que asseguram certas regularidades socais necessárias. Pretendo tão-somente reafirmar que certas rupturas reincidentes que ocorrem nos interstícios da vida pública não põem em risco a cotidianidade-embora a desafiem--, mas, ao contrário, garantem certas dinâmicas necessárias às práticas sociais geradoras da contestação e da mudança.

\section{COTIDIANO COMO ROTINIZAÇÃO}

Entre as tão distintas concepções teóricas que direta ou indiretamente abordam ou se referem ao cotidiano, paira ao menos uma tendência convergente a considerar o cotidiano como um campo da rotina. O termo não é isento de pequenas nuanças conceituais. Contudo, ele normalmente é entendido, como ressalta José Machado Pais, como algo próximo à cotidianeidade e expressa o grau de perenidade, continuidade, ou mesmo de repetição das ações diárias: “É certo que, considerado do ponto de vista da sua regularidade, normatividade e repetitividade, o quotidiano manifesta-se como um campo de ritualidades" (Pais, 2007:30).

Mesmo quando se reconhece que o cotidiano suporta uma espontaneidade quase imanente, que o torna um campo de ações apenas prováveis de acontecer, como afirma Agnes Heller (2000), não é raro o reconhecimento subsequente de que é desejável que o cotidiano seja, do ponto de vista da sua regularidade normativa, algo moralmente adequado. Nesta perspectiva clássica, não se nega que as ações cotidianas possuem alternativas e possibilidades de escolha distintas daquelas 
normalmente esperadas, mas também se afirma que, quanto mais essas ações se dispersam mediante escolhas individuais e de risco, menos se pode falar em uma decisão cotidiana (Heller, 2000:24).

O peso que se atribui à importância dessas frações criativas de rupturas das expectativas das ações cotidianas varia muito, de acordo com a abordagem em foco. José Machado Pais (2007) reconhece que o cotidiano se expressa como campo de ritualidades, mas, ao mesmo tempo, admite e defende uma abordagem do cotidiano que foque justamente nos interstícios fugidios dessa cotidianidade, com o mesmo "status ontológico" com que se analisam as ações rotineiramente previstas pela sua inserção estrutural. Este ponto de vista é obviamente heterodoxo para as principais perspectivas que abordam ou se referem ao cotidiano, uma vez que a ênfase que predomina é justamente sobre o caráter recorrente do cotidiano, como se ele fosse tão-somente o pano de fundo das ações sociais, crítica esta já feita por Michel de Certeau, autor sobre o qual me deterei mais adiante.

Nessa direção, o cotidiano é similar à categoria "espaço" na teoria social em geral, uma vez que, igualmente, essas abordagens tomam essa categoria mais como cenário passivo da vida social, uma espécie de variável dependente, seja das ações, seja das estruturas sociais. Não creio ser possível pensar sociologicamente a cidade contemporânea sem aludir a certas regularidades que imprimem uma rotinização cotidiana. É conhecida a assertiva de Simmel acerca da característica "mecânica" da vida na metrópole, em virtude da monetarização da economia, que transforma igualmente pessoas em objetos, numa espécie de engrenagem que corroi a individualidade. A atitude blasé a que se refere Simmel seria uma espécie de escapismo autodefensivo a essa uniformização do cotidiano que, embora necessária, geraria uma demasiada impessoalidade da vida urbana. Disto decorre uma inevitável reflexão: as regularidades existem, são necessárias para assegurar o que Giddens (1989) chamou de "segurança ontológica", ou "senso de confiança", mas o seu excesso pode induzir à existência da atitude blasé, comprometendo a estabilidade cotidiana, na medida em que atitudes defensivas em relação ao "estranho" do tipo "comunidades destrutivas" (Sennett, 1976), ou atitudes individualizadas do tipo blasé, incidem contrariamente às expectativas de interação rotineira que as regularidades cotidianas deveriam ter. É neste sentido que penso serem necessárias as regularidades, tanto quanto as irregularidades; tanto a ação normativamente ordenada, quanto a ação contingente. 
Deste modo, dado o caráter fragmentado e multifacetado da cultura urbana contemporânea, creio não ser igualmente possível pensar sociologicamente a cidade contemporânea sem aludir às rupturas que certas práticas sociais imprimem à vida cotidiana, tornando instáveis e rompendo certas regularidades sociais, reais ou esperadas. A discussão conceitual que dá sustentação lógica a essa ideia é reconhecidamente um terreno movediço. O desafio não é simples. Além de movediço, esse terreno é cheio de ondulações, que mais parecem os espaços estriados de Deleuze e Guatari (1997).

Obviamente que seria, aqui, inoportuna - para não dizer inexecutável - qualquer tentativa de realizar uma espécie de genealogia da noção de regularidades sociais na Teoria Social. Essa tarefa extrapola o limite e pretensões deste artigo, e já foi feita por outros autores, como Pais (2007) e Tedesco (1999). Gostaria tão-somente de sublinhar que parte dos grandes eixos analíticos da teoria social têm quase como uma obsessão a ideia de regularidades sociais, base lógica para muitas interpretações sobre o caráter recursivo do cotidiano. A base dessa acentuada preocupação transita, em geral, entre duas justificativas complementares: uma, de ordem epistemológica, outra, de natureza prática. As abordagens são variadas e fundamentam-se em aspectos e pontos de vista distintos para explicar a necessidade das regularidades sociais.

Sem pretender, aqui, incidir em simplificações grosseiras, que seriam por demais imprudentes num escopo de um único artigo, gostaria apenas de destacar - em linhas gerais - algumas abordagens que ajustaram seus focos analíticos na necessidade de certas regularidades sociais. Esse percurso se faz necessário para o argumento central proposto neste artigo, a partir das proposições de Michel de Certeau, qual seja: o cotidiano também se constitui de rupturas, e não apenas de regularidades normativamente esperadas.

Perdura certa herança parsoniana na perspectiva que reafirma o caráter recursivo do cotidiano. A Teoria dos Sistemas de Talcott Parsons (1967), cuja ênfase que atribui à necessidade explicativa da integração social permeia boa parte do pensamento sociológico contemporâneo, foi, talvez, uma das primeiras teorizações mais sistemáticas da ideia de regularidade na teoria social moderna. Em outra direção, mas igualmente focado na concepção de regularidade, Anthony Giddens pode ser considerado outro representante das chamadas teorias totalizan- 
tes. Em sua Teoria da Estruturação, Giddens atribui à rotinização papel central na ideia de recursividade e monitoramento reflexivo da ação: "O termo 'cotidiano' condensa exatamente o caráter rotinizado que a vida social adquire à medida que se estende no tempo e espaço. [...] A rotinização é vital para os mecanismos psicológicos por meio dos quais um senso de confiança ou de segurança ontológica é sustentado nas atividades cotidianas da vida social" (Giddens, 1989:xix).

Embora o esquema de Giddens reafirme uma normatividade, assentada em uma consciência discursiva e derivadamente racionalizada, ele dá especial atenção ao que chama de "consciência prática" como fundamental para sua teoria. Esta consciência se refere às experiências subjetivas dos atores, de modo que Giddens entende que as regularidades não resultam somente do caráter normativo, mas, também, de certa expectativa que os próprios agentes mantêm em relação a como os outros devem agir. Em Giddens, portanto, as regularidades existem, são necessárias e asseguradas pelos atos da consciência prática. Esta perspectiva pode parecer mais flexível, mas continua a apostar que o cotidiano tenderá a permanecer estável em função do que chama de "monitoramento reflexivo da ação": o monitoramento reflexivo da atividade é uma característica crônica da ação cotidiana e envolve a conduta não apenas do indivíduo, mas também dos outros (ibid.:4).

Para o desdobramento subsequente da análise aqui proposta, gostaria de sublinhar - igualmente em linhas gerais - três diferentes perspectivas que tratam o cotidiano não mais como regularidade, mas como jogo interativo. Refiro-me às abordagens do Interacionismo simbólico de Erving Goffman, da Hermenêutica de Hans-Georg Gadamer, e da Teoria das Práticas de Pierre Bourdieu.

A primeira, embora compartilhe com a fenomenologia a ideia preponderante da intersubjetividade como definidora dos contextos de ação, não opera uma redução drástica do peso da estrutura, na medida em que a considera como um dos elementos que participam da formação dos contextos de ação. Contudo, essa participação é passiva: as estruturas são somente os cenários dos processos interativos. A analogia dramatúrgica é utilizada por Goffman não apenas como retórica: os conceitos básicos do Interacionismo são de caráter cênico, de modo que se entende que o ator social desempenha um dado papel, mediante uma representação na qual ele segue regularidades cotidianamente influenciadas pelo mundo social e externo (o que o aproxima de Par- 
sons), mas retém, esse mesmo ator, a capacidade de definir a situação social na qual esse papel está situado e como deve se mover/atuar (o que o afasta da teoria dos sistemas). Dessa forma, o ator, em Goffman, representa mediante seus próprios parâmetros de definição da situação social, de forma intersubjetiva. O cotidiano é, assim, algo que resulta dessa capacidade de o ator definir a situação em que atua rotineiramente, mas não necessariamente de modo fixo.

Para o que nos interessa especificamente aqui, gostaria apenas de reter da Hermenêutica de Gadamer o centro da sua reflexão sobre a inserção do sujeito nos contextos cotidianos de interação. Gadamer faz isso utilizando a ideia de jogo como a autoexperiência hermenêutica e tem a intenção de superar o debate "ser" e "essência", que separaria as abordagens objetivistas das subjetivistas, aludindo à inserção nos processos interativos como um "ser-absorvido-no-jogo" (Gadamer, 2004). A ideia básica é que o próprio sujeito se forma no ato de jogar. Ele nem antecede as regras do lúdico jogo social, nem nele adentra mediante estruturas predeterminadas. O sujeito hermenêutico é constituído no ato do jogo, e por ele determinado. Desta forma, o verdadeiro sujeito do jogo é o próprio jogo. Nos termos do que nos interessa: o cotidiano é lúdico. Nem é estruturalmente determinado, nem é tão volúvel às significações do "eu" individualizado, ou do "eu interativo (que, embora interativo, ainda é tão-somente o "eu-que-interage"). Na perspectiva de Gadamer, há uma sutil variante em relação às abordagens fenomenológicas e interacionistas: não existe um sujeito que interage; o sujeito é o próprio jogo de interações cotidianas. É neste âmbito que se formam "sujeitos", imersos e dependentes das regras (variáveis em cada situação, mas configuradas em cada jogo especifico) do próprio viver cotidiano.

Esta ênfase explicativa do agir cotidiano numa espécie de interação que nem se enquadra em uma perspectiva objetivista de estruturas determinantes da ação, nem se reduz à abordagem subjetivista que foca a autonomia cognoscitiva da ação num sujeito autônomo, é retomada pela Teoria da Prática de Pierre Bourdieu (2002), em seu conhecido conceito de habitus. Bourdieu segue a mesma preocupação de Giddens (já expressa nas reflexões, anteriores aos dois, de Norbert Elias (2005), com o conceito de configurações) em encontrar uma explicação que não se reduza simplesmente aos parâmetros da estrutura, por um lado, e da ação, por outro, sem, contudo, abandonar os efeitos que essas categorias têm sobre a ação. 
Sabe-se que o conceito de habitus recusa tanto o objetivismo estruturante quanto o subjetivismo voluntarista, dando ênfase, muito similar ao modo da hermenêutica de Gadamer, às práticas (ou jogo de interação, para Gadamer), como elemento definidor da ação. Por habitus entende Bourdieu um "sistema de disposições" da ação. Para o que aqui nos interessa mais de perto, é necessário sublinhar que o caráter duradouro dessas disposições depende de "certas regularidades associadas a um meio ambiente socialmente estruturado" (Bourdieu, 2002:163).

Essas regularidades, contudo, não são, em Bourdieu, resultado de qualquer predeterminação: elas são fruto das práticas socais advindas de estruturas, estruturadas que são, ao mesmo tempo regulares e reguladas (bem ao modo do monitoramento reflexivo de Giddens), sem necessariamente serem produtos de normatividade expressa em papéis sociais que antecedem a ação. Numa espécie de orquestra sem maestro, para usar a própria analogia de Bourdieu, as ações são recorrentes dada a probabilidade de convergência de sentido que existe entre as disposições (ao modo da ideia weberiana de adequação de sentido das ações racionais com relação a fins): "do facto de a identidade das condições de existência tender a produzir sistemas de disposições semelhantes (pelo menos parcialmente), a homogeneização (relativa) dos habitus daí resultantes está no principio de uma harmonização objectiva das práticas e das obras de molde a conferir-lhe regularidade [...]" (ibid.:169, ênfase no original).

Embora entenda que o habitus abriga uma intenção estratégica, apreende Bourdieu que essa recorrência da ação segue tão-somente uma "estimativa de probabilidade". A abordagem de Bourdieu, contudo, pode parecer ambígua quando tenta enfrentar a explicação da recorrência da ação que gera a rotinização da vida cotidiana. Por um lado, ele reconhece que essa recorrência das práticas cotidianas produzida pelo habitus permite explicar as situações imprevistas (as zonas turvas do cotidiano às quais se refere José Machado Pais), na medida em que entende ser a estratégia da ação algo que se define em seu próprio curso, podendo suportar outras estratégias possíveis. Por outro lado, embora rejeite uma teleologia da ação (o que descarta a existência de uma filosofia do sujeito na Teoria da Prática), Bourdieu parece, ao final, se render relativamente ao apelo das estruturas ao afirmar que, mesmo nestas situações de alteração das estratégias, elas tendem (em suas próprias palavras): "sempre a reproduzir as estruturas objetivas cujo produto em úl- 
tima análise? são" (ibid.:14). É dessa forma que o habitus produz um conjunto de disposições semelhantes (Bourdieu, 2008) que se forma historicamente mediante práticas individuais e coletivas "em conformidade com os esquemas engendrados por essa mesma história" (Bourdieu, 2002).

Obviamente que inexiste em Bourdieu uma teoria da história, no sentido de uma teleologia do dever-ser, seja ela objetivamente dada pelas estruturas ou subjetivamente construída por consciências individuais. Apesar desse aspecto altamente positivo, o esquema analítico de Bourdieu parece preso em sua própria armadilha, que pode ser considerada semelhante à situação de Giddens: sempre que se tenta superar o binarismo da estrutura e da ação (ou das explicações objetivistas e subjetivistas) por um caminho ainda demarcado por esse próprio binarismo, acaba-se por dele não escapar; e a solução explicativa parece sempre tender a manter o binarismo (ou dualidade da estrutura, como quer Giddens) como marcos de referência para pensar a possibilidade de ações que pretendem escapar desse binarismo sem, contudo, com ele romper. Em certa medida, poderíamos indagar se o conceito de habitus se sustentaria logicamente (assim como o de monitoramento reflexivo da ação, de Giddens) fora das duas margens analíticas do mesmo caminho que demarca o binarismo entre estrutura e ação. Talvez por isso tenha Michel de Certeau duvidado do alcance do conceito de habitus para os estudos sobre cotidiano, uma vez que as estratégias da ação decorrentes do habitus acabam por criar uma espécie de "dogma": "Nos termos em que o problema se coloca para ele, Bourdieu, deve encontrar alguma coisa que ajuste as práticas às estruturas e que explique também os desníveis entre eles" (Certeau, 1994:125).

É neste ponto que, possivelmente, o conceito de habitus não se desvencilhe totalmente das estruturas: no jogo da interiorização das estruturas mediante a aquisição (processo educacional) e na exteriorização processual dessas estruturas adquiridas por meio do habitus, as práticas e estratégias de ação tendem, logicamente, a dar sustentação às estruturas, imprimindo-lhes as necessárias regularidades sociais. Embora o habitus não predefina o conteúdo das ações (uma vez que consistem em disposições), ele delimita, contudo, a forma. Talvez por isso Certeau tenda a recusar o que chama de "a sedução do conceito de habitus", afirmando que ele acaba por ser um "lugar dogmático", posto que não dá conta de explicar como certas práticas não se limitam a dar repostas a determinadas conjunturas: "Examinando escrupulosamente 
as práticas e sua lógica - de maneira que não tem, sem dúvida, equivalente desde Marcel Mauss - eles os reduzem, enfim, a uma realidade mística, o habitus, destinada a colocá-los sob a lei da reprodução" (Certeau, 1994:127).

Para além dessas reconhecidas regularidades que adensam as explicações sobre a vida cotidiana, caberia, igualmente, refletir sobre suas rupturas drásticas na forma de afrontamentos deliberados em relação às disposições habituais: táticas escorregadias que subvertem as estratégias postuladas pelo poder (Certeau, 1994) ou dos contra-usos (Leite, 2007) dos espaços cotidianos na experiência urbana contemporânea.

\section{Cotidiano e as Artes de Fazer}

Uma das mais importantes abordagens contemporâneas sobre vida cotidiana está na reflexão de Michel de Certeau, em seu L'Invention du Quotidien, de 1974. Historiador, Certeau deu inegável contribuição aos estudos de Sociologia Urbana, ao abordar as práticas e artes de fazer da vida cotidiana. Em estilo fragmentado e muitas vezes metafórico, o texto de Certeau é dedicado, como ele próprio esclarece, ao "homem ordinário: Herói comum. Personagem disseminada. Caminhante inumerável" (Certeau, 1994:57).

O primeiro aspecto relevante é a total ruptura operada por Certeau no binarismo conceitual estrutura e ação. O foco é outro: não se trata de investigar as determinações estruturais do agir cotidiano, nem de perceber as ressonâncias das ações comuns intersubjetivas na conformação estrutural das regularidades sociais. O pressuposto certeauniano central para analisar a vida cotidiana são os lances táticos e situacionais que informam as artes de fazer. Embora retenha aproximações com a própria Teoria da Prática de Bourdieu (a qual critica) e com a hermenêutica de Gadamer (a quem pouco se refere), a análise de Certeau segue uma lógica própria ao analisar a ação cotidiana em suas feições predominantemente conflitantes:

Meu trabalho não visa diretamente a constituição de uma semiótica. Consiste em sugerir algumas maneiras de pensar as práticas cotidianas dos consumidores, supondo, no ponto de partida, que são do tipo tático. Habitar, circular, falar, ler, ir às compras ou cozinhar, todas essas atividades parecem corresponder às características das astúcias e das surpresas tática: gestos hábeis do "fraco" na ordem estabelecida pelo "forte", arte de dar golpes no campo do outro, astúcia de caçadores, mobili- 
dades nas manobras, operações polimórficas, achados alegres, poéticos e bélicos. (Certeau, 1994:103)

A perspectiva de Certeau é heterodoxa: para ele, o cotidiano não se define pelas regularidades socais, ainda que possa ser formado por recorrências. Longe de ser aquele cotidiano trivial de Goffman, ou a vida normativa dos papéis sociais de Parsons, o cotidiano para Certeau são procedimentos. A partir de um diálogo crítico com a Microfísica do Poder, de Michel Foucault; com a Teoria da Prática, de Pierre Bourdieu, e a abordagem do antropólogo e historiador Marcel Detienne, Certeau aproxima seu conceito de cotidiano à noção de jogo. As ações são, assim, proporcionais às situações vividas.

Contudo, esse jogo não é nem o "jogo-em-si" de Gadamer, nem o jogo dramático de Goffman. Trata-se de um jogo articulado de práticas de dois tipos: as estratégias e as táticas. Com esse par de conceitos, Certeau rompe com a definição de cotidiano como rotinização para dar lugar à ideia de cotidiano como movimento.

Outra definição preliminar, contudo, se faz necessária ao entendimento dessa distinção. Certeau utiliza a noção de "algo próprio", ou "próprio", como "a vitória de lugar sobre o tempo. [...] é o domínio do tempo pela fundação de um lugar autônomo" (ibid.:99). Essa noção é fundamental para a distinção entre táticas e estratégias: na metafórica bélica de Certeau, esse "próprio" corresponde a uma espécie de demarcação espacial (uma trincheira, por assim dizer), cuja base permite gerir as ações em direção a exterioridades (alvos específicos). Desse modo, diz Certeau: "Chamo de estratégia o cálculo (ou a manipulação) das relações de forças que se torna possível a partir do momento em que um sujeito de querer e poder (uma empresa, um exército, uma cidade, uma instituição cientifica) pode ser isolado" (id.).

Desse modo, as estratégias são as práticas que postulam "um lugar suscetível de ser circunscrito como algo próprio", sendo, portanto, a estratégia organizada pelo "postulado de um poder". As táticas, por sua vez, são sistemas de astúcias que se infiltram na heterogeneidade social; elas se esquivam, se insinuam, se contrapõem: “Chamo por tática a ação calculada que é determinada pela ausência de um próprio. Então nenhuma delimitação de fora lhe fornece a condição de autonomia. A tática não tem lugar senão o do outro" (Certeau, 1994:100). 
Determinada pela "ausência de poder", a tática é a "arte do fraco", por isso as opera "golpe por golpe": "a tática tem que utilizar, vigilante, as falhas que as conjunturas particulares vão abrindo na vigilância do poder proprietário. Aí vai caçar. Cria ali surpresas. Consegue estar onde ninguém espera. É astúcia" (ibid.:101).

O cotidiano como práticas, sejam elas estratégias ou táticas, subverte os parâmetros conceituais que o entendem como rotinas ou regularidades, para enfatizar o caráter inerente de disputas e rupturas. Ao contrário de pensar as práticas cotidianas na encruzilhada do binarismo estrutura e ação, Certeau enfatiza os procedimentos variáveis e labirínticos da ação, segundo a lógica processual e dinâmica das relações de poder da vida cotidiana. As estratégias, pensadas em contextos urbanos, equivalem ao que Sharon Zukin (1995) chamou de paisagens de poder para designar as inscrições urbanas dos detentores do poder; do mesmo modo que as táticas seriam o vernacular que se contrapõe às paisagens de poder, infiltrando-se na ordem urbana e criando fissuras que possibilitam vislumbrar as formas destoantes de uma vida cotidiana supostamente estável e regular.

A ênfase dada por Certeau ao cotidiano como uma espécie de campo de batalha, cujas táticas precisam encontrar modos inventivos de escape e confrontação em cada situação, rompe não apenas com o caráter normativo da ação social cotidiana, como também realça um aspecto pouco contemplado em outras abordagens: as relações de poder que incidem de modo substancial na construção social da vida pública cotidiana. A noção de cotidiano como práticas, em Certeau, portanto, permite que se analise formas distintas de apropriação do espaço, a formação de lugares e o rompimento de fronteiras que demarcam socioespacialmente a vida urbana. Mais ainda: sua perspectiva, na direção paralela à microfísica foucaultiana, está centrada nas práticas que desafiam o espaço disciplinar.

Nesse ponto, é importante sublinhar o momento em que a análise de Certeau escapa das possíveis armadilhas do binarismo conceitual antes mencionado, que tende ora para as explicações objetivistas, ora para as subjetivistas. A preocupação de Certeau não é estabelecer condicionantes das práticas sociais como sujeitos, nem afirmar a preponderância dos contextos e das estruturas; menos ainda, de estabelecer qualquer terceira via. A preocupação de Certeau é, ao contrário, compreender como as práticas cotidianas, cujo ser-aí só se forma na própria 
prática, escapam dos condicionantes sociais nas quais estão sujeitas, ainda que sem deles fujam totalmente. "Eu gostaria de acompanhar alguns dos procedimentos - multiformes, resistentes, astuciosos e teimosos - que escapam da disciplina sem ficarem mesmo assim fora do campo que exerce, e que deveriam levar a uma teoria das práticas cotidianas, do espaço vivido e da inquietante familiaridade da cidade" (Certeau, 1994:175).

Não sem razão, a base empírica para uma teoria do cotidiano em Certeau reside, sobretudo, no que ele denomina "caminhadas pela cidade". Como operações enunciadoras, "a caminhada afirma, lança suspeita, arrisca, transgride, respeita [...]" (ibid.:179). Para Certeau, os passos pela cidade são uma espécie de matéria-prima das táticas cotidianas, mediante os quais as diferentes modalidades de ação entram em jogo: "Caminhar é ter falta de lugar" (ibid.:183).

Isso nos leva a outro par de conceitos, fundamental em sua abordagem: a distinção entre espaço e lugar, na qual o espaço corresponde à ausência de posições definidas e, por isso, é uma ordem móvel que propicia vislumbrar as diferentes experiências espaciais da vida cotidiana; e o lugar corresponde, opostamente, a certas configurações mais estáveis de posições. O que o primeiro tem de provisório, o segundo tem de permanente. Assim, enquanto o lugar retém o "próprio", correspondendo, assim, às práticas do tipo estratégicas, o espaço corresponde às práticas táticas. Por isto Certeau vai afirmar que o "o espaço é um lugar praticado" (ibid.:202).

Em outras palavras, como já pude sugerir em outra ocasião, tendo como ponto de partida Certeau, devemos entender por lugar algo que resulta de uma demarcação física e/ ou simbólica no espaço, cujos usos o qualificam e lhe atribuem sentidos diferenciados, orientando ações sociais e sendo por estas reflexivamente delimitado. Um lugar é sempre um espaço de representação, cuja singularidade é construída pela "territorialidade subjetivada" (Guattari, 1985), mediante práticas sociais e usos semelhantes (Leite, 2007:283). A única observação que se faz ainda necessária, ampliando a distinção de Certeau, seria a de assinalar que os lugares também podem resultar das táticas, e não apenas das estratégias, na medida em que a formação das identidades urbanas também opera recortes no espaço como forma de demarcar, de modo relativamente estável, lugares como "territórios de subjetivação". 
Não há, contudo, inflexibilidade no esquema analítico de Certeau: tanto as práticas podem ajustar espaços a lugares, como subverter lugares em espaços. Há, entre essas categorias, passagens que permitem entender a dinâmica das fronteiras flexíveis que marcam a vida cotidiana. Nesse aspecto, Certeau lembra Simmel (1986), quando afirmava que a coexistência das diferentes pessoas ou grupos somente se dava por "entre" os lugares do espaço. São justamente esses entre-lugares que informam a diversidade da vida cotidiana e suas diferentes enunciações (Bhabha, 1998). Esta mesma perspectiva é compartilhada por Félix Guattari quando afirma que "o ser humano contemporâneo é fundamentalmente desterritorializado" (Guattari, 1992:169). Queria Guattari sublinhar exatamente a existência de certo nomadismo que permeia a formação das subjetividades cotidianas, alheias a pontos fixos de referência (nos termos de Certeau, a capacidade de as práticas desafiarem o espaço disciplinar). Essa aproximação entre Certeau e Guattari não me parece fortuita e é com ela que gostaria de finalizar minha reflexão.

\section{ESPAÇOS ENOBRECIDOS: A INVERSÃO DO COTIDIANO}

No ponto em que a análise de Certeau mais adentra a crítica à ideia de um usuário colonizado pelo espaço disciplinar é o momento em que ela mais se aproxima de alguns pontos centrais da crítica à autocentralidade do sujeito, realizada pela Teoria Social pós-moderna.

Penso que essa aproximação acaba por revelar um duplo valor heurístico para a compreensão da cultura urbana contemporânea: por permitir apreender a fugacidade de certas ações cotidianas que, embora fugazes, não deixam de compor as relações diárias nas grandes cidades; e por possibilitar entender a dimensão demasiado conflituosa da vida urbana contemporânea que, embora conflituosa, não faz morrer o espaço publico, mas o ressignifica à luz das diferentes práticas sociais.

A desterritorialização urbana a que se refere Guattari reconhece o sentido predominantemente desordenado da cultura urbana contemporânea, assim como reconhece Certeau o caráter polifórmico do andante que inscreve, nos passos pela cidade, os diferentes jogos de astúcia do agir. O grau de dispersão de significados atribuídos aos espaços e a multiplicidade de estilos de vida tornam volátil a rigidez dos lugares que parecem ceder à pressão dos "espaços como lugar praticados". Para Certeau, há uma espécie de mal-estar na contemporaneidade, que 
se refere à dissonância entre a flexibilidade da cultura urbana e a planificação urbanística:

A análise desliza em toda parte sobre a incerteza que prolifera nos interstícios do cálculo, visto que ela não está ligada à enganosa estatística dos sinais objetivos (comportamentos, imagens etc.). Assim, maneiras de utilizar o espaço fogem à planificação urbanística: capaz de criar uma composição de lugares, de espaços ocupados e espaços vazios, que permite ou impedem a circulação, o urbanista é incapaz de articular essa racionalidade do concreto com os sistemas culturais, múltiplos, fluidos, que organizam a ocupação efetiva dos espaços internos [...] ou externos [...] e que os debilitam com vias inumeráveis. (Certeau, 2001:233)

Como já pude sugerir em outro momento (Leite, 2009), essa flexibilização desordenada das fronteiras urbanas, cujos usos são dissonantes, pode ser considerada reflexo prático dos amplos processos de descentramento do sujeito a que se refere Stuart Hall (2006). Se aquela visão simmeliana do blasé como mecanismo de autoconservação já não encontra espaços para sua expressão, será que o flâneur de Walter Benjamin (1997) sobreviveria, com seu andar a esmo, numa sociedade marcadamente violenta por códigos territoriais segregacionistas?

É nesse impasse, típico da chamada condição pós-moderna (Jameson, 1997; Baudrillard, 1984; Harvey, 1992, Featherstone, 1995), que a teoria da prática cotidiana de Certeau talvez possa desvendar sua mais atual contribuição, na medida em que somente pensando o cotidiano como práticas que refletem as relações de poder existentes poder-se-ia explicar como a vida cotidiana se mantém, mesmo com a forte presença de sociabilidades públicas fragmentadas em um espaço urbano marcado pelas reivindicações da diferença (Derrida, 2006; Deleuze, 2006), que muitas vezes resultam no que Antonio Arantes (2000) denominou de "guerra dos lugares".

Como se sabe, os diferentes modos de vida na cultura contemporânea nem sempre são reconciliáveis, uma vez que carregam certa aversão ao estranho. As chamadas tribos urbanas (Maffesoli, 2005) também mantêm suas próprias recusas, justamente quando demarcam seus lugares, como espaços praticados (Leite, 2008). Em todos esses casos, porém, persistem itinerários nos quais esses encontros são, por vezes, inevitáveis, ou, mesmo, desejados. Essa quase inevitabilidade ocorre precisamente mediante as práticas, sobretudo as do tipo táticas, que ocorrem 
justamente nos espaços certeaunianos, cujas zonas fronteiriças permitem que surja a insinuação que perturba o cotidiano e desafia o espaço disciplinar, tomando a forma de contra-usos.

Um dos espaços para a privilegiada observação dessas "perturbações" táticas de contra-usuários são justamente aqueles sítios históricos que passaram por processos de gentrification. Por gentrification, ou enobrecimento, entende-se, aqui, um tipo específico de intervenção urbana que altera a paisagem urbanística e/ou arquitetônica com forte apelo visual, adequando a nova paisagem às demandas de valorização imobiliária, de segurança, de ordenamento e de limpeza voltadas ao uso, ou à reapropriação, por parte das classes médias e altas (Leite, 2010).

Esses espaços ganham considerável visibilidade em decorrência de sua nova atratividade em virtude das intervenções urbanas que alteram seus usos. Em razão disso, fazem convergir pessoas e grupos muito distintos em suas feições identitárias, que disputam o espaço de modo prático e simbólico. Nestes espaços enobrecidos, a vida cotidiana parece cindida em suas características recursivas. Dada a visível fragmentação dos espaços e a flagrante segregação socioespacial existentes, as relações cotidianas guardam certas instabilidades que contrariam a noção de rotinização atribuída à vida social.

Estudos recentes sobre esses processos em cidades brasileiras e portuguesas (Leite, 2010) sugerem ser esta uma das recorrentes características dos processos de enobrecimento. Em geral, estes processos são precedidos por um estado de declínio da área urbana, muitas vezes causado pela evasão de moradores de média e alta rendas, para outras regiões das cidades, cuja transferência acarreta perda da funcionalidade da área pela deterioração das edificações e dos mobiliários urbanos. Populações remanescentes permanecem nestes espaços fisicamente degradados, muitas vezes imprimindo ao local certa aura de marginalidade.

A despeito da decadência física, esses espaços continuam a guardar forte significado histórico para a cidade, em decorrência de seu acervo patrimonial. Reativados pelos processos de enobrecimento, parte desses antigos moradores e usuários são confrontados pelas novas exigências estéticas e padrões de consumo que moldam essas intervenções urbanas e arquitetônicas. Antigos casarões e armazéns portuários são transformados em áreas de lazer e consumo diferenciado, e submetidos a forte sistema de vigilância. O resultado implausível dessas inter- 
venções tem sido uma forte segregação socioespacial, a despeito de terem a intenção - ao menos conceitualmente - de restaurar os espaços centrais da cidade para uma plena vida cotidiana pública.

Muitos sãos os casos que poderiam referendar essa conclusão: destacaria, apenas, para efeito de rebatimento empírico, os casos de Puerto Madero, em Buenos Aires, e da Ribeira do Porto, na cidade portuguesa do Porto. A exemplo de outras experiências, tais como Lisboa, Recife, Londres, Barcelona e Salvador, esses dois processos ocorreram em históricas áreas portuárias. Não por acaso essas regiões são escolhidas para esse tipo de intervenção; elas conjugam duas importantes características para radicais alterações de usos e usuários: têm relevância histórica e simbólica para a cidade e, de modo geral, não apresentam grande adensamento residencial. Em outras palavras: são áreas marginalizadas, povoadas por aquele homem ordinário a que se referia Certeau.

Puerto Madero e Ribeira do Porto foram, respectivamente, áreas de extrema importância para as economias portenha e portuguesa (Lacarrieu, 2006; Peixoto, 2006) e tiveram o apogeu da sua importância urbana na primeira metade do século $X X$, marcada pelos finos Cafés e pelas sociabilidades de rua. O lento e inexorável processo de degradação física do conjunto urbanístico e arquitetônico coincide com o arrefecimento das atividades portuárias, levando esses espaços a perder sua centralidade e, subsequentemente, os investimentos que lhes asseguravam a sua necessária conservação.

É sobretudo a partir dos anos 1990 do século passado que o patrimônio histórico é retomado como mecanismo de revalorização da cultura local e como instrumento para a concorrência intercidades (Fortuna, 1997). O patrimônio edificado é ressignificado à luz do city marketing, transformando espaços antes degradados em áreas de alto valor cultural e de mercado. É nesse contexto que Puerto Madero e Ribeira do Porto passaram por profundas intervenções de revitalização urbana, com vistas à adequação desses espaços históricos para as práticas de consumo.

Em quase todos os projetos que pretendem "revitalizar" centros históricos há o discurso de recuperar certa vida cotidiana pública, considerada perdida, ignorando abertamente antigos moradores, andarilhos, sem-teto, boêmios e prostitutas que quase sempre ficaram morando/utilizando esses espaços. Ao desconsiderarem esses agentes como 
partícipes, os projetos de revitalização incorrem em duplo - porém compreensível - equívoco: tomam a cidade como locus de alguns, ao mesmo tempo em que discursam sobre a cidade de todos. O equívoco é compreensível porque a natureza política da intenção revitalizadora é perceptível: o processo de enobrecimento não busca promover formas de inserção social, nem de democratização dos usos dos espaços urbanos.

As consequências desses processos são bem conhecidas: paisagens de poder são construídas a elevados custos sociais. Em meio à monumentalidade arquitetônica e à curetagem social (Certeau, 1994) ressoam a expulsão de moradores, a segregação de usuários e a criação de uma vida cotidiana "rotinizada" e ordenada pelos aparatos de segurança.

Na proporção direta da espetaculização da cultura e da tentativa de disciplinar o espaço, a vida cotidiana parece estar longe daquela rotinização preconizada. Ao contrário, ressurge repleta de fissuras, confrontações, contra-usos. As assimetrias do poder nos espaços enobrecidos constrangem, mas não aniquilam as deambulações daqueles homens ordinários que taticamente demarcam suas práticas sociais no espaço vernacular e revelam a dimensão politicamente conflituosa da vida cotidiana.

É nesse sentido que a noção certeauniana de vida cotidiana como um jogo de táticas e estratégias revela seu potencial explicativo: para além de uma concepção de um cotidiano rotinizado, seja pela normatividade, papéis sociais ou intersubjetividades, deve-se pensar, também, nas confrontações que parecem inverter o cotidiano como rotina e que marcam o cotidiano na contemporaneidade e enunciam a inversão na experiência urbana: poética e bélica inversão do cotidiano.

(Recebido para publicação em julho de 2009)

(Reapresentado em março de 2010)

(Versão definitiva em outubro de 2010) 


\section{Rogerio Proença Leite}

\section{REFERÊNCIAS BIBLIOGRÁFICAS}

ARANTES, Antonio A. (2000), Paisagens Paulistanas: Transformações do Espaço Público. Campinas, Ed. Unicamp.

AUGÉ, Marc. (1994), Não-lugares: Introdução a uma Antropologia da Supermodernidade. Campinas, Papirus.

BAUDRILLARD, Jean. (1984), Para uma Crítica da Economia Política do Signo. Lisboa, Edições 70 .

BENJAMIN, Walter. (1997), "Paris, Capital do Século XIX", in C. Fortuna (org.), Cidade, Cultura e Globalização: Ensaios de Sociologia. Oeiras, Celta Editora, pp. 67-80.

BHABHA, Homi K. (1998), O Local da Cultura. Belo Horizonte, Editora UFMG.

BOURDIEU, Pierre. (2002), Esboço de uma Teoria da Prática. Oeiras, Celta. . (2008), A Distinção: Crítica Social do Julgamento. São Paulo, Edusp.

CERTEAU, Michel. (1994), A Invenção do Cotidiano: Artes de Fazer. Petrópolis, Vozes. . (2001), A Cultura no Plural. Campinas, Papirus.

DELEUZE, Gilles. (2006), Diferencia y Repeticion. Buenos Aires, Amorrortu. ãã e GUATTARI, Félix. (1997), Mil Platôs: Capitalismo e Esquizofrenia. São Paulo, Editora 34 , vol. 5 .

DERRIDA, Jacques. (2006), Gramatologia. São Paulo, Perspectiva.

ELIAS, Norbert. (2005), Introdução à Sociologia. Lisboa, Edições 70.

FEATHERSTONE, Mike. (1995), Cultura de Consumo e Pós-Modernismo. São Paulo, Studio Nobel.

FORTUNA, Carlos. (1997), "Destradicionalização e Imagem da Cidade”, in C. Fortuna (org.), Cidade, Cultura e Globalização: Ensaios de Sociologia. Oeiras, Celta Editora, pp. 231-257.

GADAMER, Hans-Georg et alii. (2004), Truth and Method. New York, Continuum International Publishing Group.

GOFFMAN, Erving. (1985), A Representação do Eu na Vida Cotidiana (8a ed.). Petrópolis, Vozes.

GUATTARI, Félix. (1985), "Espaço e Poder: A Criação de Territórios na Cidade". Espaço e Debates, no 16, pp. 45-59.

HALL, Stuart. (2006), A Identidade Cultural na Pós-Modernidade (11a ed.). Rio de Janeiro, DP\&A Editora.

HELLER, Agnes. (2000), O Cotidiano e a História (6a ed.). São Paulo, Paz e Terra.

JAMESON, Fredric. (1997), Pós-Modernismo: A Lógica Cultural do Capitalismo Tardio. São Paulo, Ática.

LACARRIEU, M. et alii. (2006), “Procesos de Transformación Urbana en Lugares Centrales y Periféricos del Área Metropolitana de Buenos Aires: Gano el Urbanismo Escenografico?", in H. Frúgoli et alii (orgs.), As Cidades e seus Agentes: Práticas e Representações. Belo Horizonte/São Paulo, PUC-MINAS/EDUSP, pp. 98-127. 
LEITE, Rogerio Proença. (2007), Contra-Usos da Cidade (2a ed.). Campinas, Ed. Unicamp/São Cristóvão, EdUFS.

. (2008), “Gentrification e Cultura Urbana”. Revista Crítica de Ciências Sociais, no 83, pp. 35-54.

. (2009), “Espaço Públicos na Pós-Modernidade”, in C. Fortuna e R. P. Leite (orgs.), Plural de Cidade: Novos Léxicos Urbanos. Coimbra, Almedina, pp. 187-204.

. (2010), “A Exaustão das Cidades: Antienobrecimento e Intervenções Urbanas em Cidades Brasileiras e Portuguesas". Revista Brasileira de Ciências Sociais, no 72, pp.73-88.

MAFFESOLI, Michel. (2005), A Transfiguração do Político: A Tribalização do Mundo. Porto Alegre, Sulina.

MARTINS, José de Souza. (2000), A Sociabilidade do Homem Simples. São Paulo, Hucitec.

PAIS, José Machado. (2007), Sociologia da Vida Quotidiana: Teoria, Métodos e Estudos de Caso (3a ed.). Lisboa, Imprensa de Ciências Sociais.

PARSONS, Talcott. (1967), The Structure of Social Action. New York, The Free Press.

PEIXOTO, Paulo. (2006), O Passado Ainda Não Começou: Funções e Estatuto dos Centros Históricos no Contexto Urbano Português. Coimbra, Tese de Doutorado em Sociologia, Universidade de Coimbra.

SENNETT, Richard. (1976), The Fall of Public Man. New York/London, W.W. Norton \& Company.

SIMMEL, Georg. (1986), Sociologia 2: Estudios sobre las Formas de Socialización. Madri, Alianza Universidad.

TEDESCO, João Carlos. (1999), Paradigmas do Cotidiano. Santa Cruz do Sul, EDUNISC.

ZUKIN, Sharon. (1995), The Cultures of Cities. Cambridge, Mass., Blackwell. 


\section{Rogerio Proença Leite}

\section{ABSTRACT \\ Inversion in Everyday Life: Social Practices and Breaks in Contemporary Urban Life}

This article focuses on key approaches from social theory to analyze routine everyday life in order to affirm that certain frequent breaks occurring in the interstices of public life do not place the notion of daily existence at jeopardy although they challenge it; on the contrary, they guarantee certain dynamics that are necessary for the social practices that spawn challenge and change. With an emphasis on Michel de Certeau's Theory of Practices, the article discusses the practices that challenge the disciplinary spaces through either daily tactics or counter-uses, with a view towards understanding the dynamic processes of everyday life in contemporary urban culture.

Key words: everyday life; social tactics; Michel de Certeau

\section{RÉSUMÉ \\ L'Inversion du Quotidien: Pratiques Sociales et Ruptures dans la vie Urbaine Contemporaine}

L'article analyse dans une optique théorique quelques versants de la théorie sociale sur le quotidien comme l'action de la routine pour réaffirmer que certaines ruptures réincidentes qui se produisent dans les interstices de la vie publique ne mettent pas en risque la quotidienneté - bien qu'elles la défient mais au contraire, garantissent certaines dynamiques nécessaires aux pratiques sociales génératrices de la contestation et du changement. Avec un accent sur la Théorie des Pratiques de Michel de Certeau, la réflexion aborde les pratiques qui défient l'espace disciplinaire soit au moyen de tactiques soit encore de contre-usages quotidiens, en prenant en considération la compréhension des processus dynamiques du quotidien dans la culture urbaine contemporaine.

Mots-clés: quotidien; tactiques sociales; Michel de Certeau 